\title{
GAYA KEPEMIMPINAN DI TENGAH ARUS PERPINDAHAN ZAMAN PT. KOMPAS GRAMEDIA MAKASSAR
}

\author{
Sukaini \\ Universitas Teknologi Sulawesi Selatan \\ Email: chita.mylife@gmail.com
}

\begin{abstract}
This research is based on several factors that tickled researchers to try more in reviewing, the first is the advancement of KOMPAS as a print media from the time of the time, second is the ability of the Kompas to remain exist in this internet era. In the world of print media KOMPAS name is a medium that can not be underestimated KOMPAS is one of the pioneers of national print media that succeeded in several eras or eras, in the era of the old Order Kompas is the first commitment of independent print media. In the era of the new Order Kompas increasingly to intensify his legs as a trusted media cetak. However, Kompas's journey was not as easy as that in the new Order era. Many twists are faced by Kompas but this does not dampen the board of directors from Kompas to keep a print media Kompas that does not stand by and stands on the basis of its independence. In the era of Kompas reform was one of the drivers of print media to tell about the reform movement at that time. The above things tickled a sense of ignorance from researchers to research the main factor of the strength of the Kompas, Terkusus PT. Kompas Gramedia south Sulawesi.
\end{abstract}

Keywords: Leadership style, leadership, human resource management

\begin{abstract}
ABSTRAK
Penelitian ini didasari atas beberapa faktor yang menggelitik peneliti untuk mencoba lebih dalam mengkaji, yang pertama adalah kemajuan dari KOMPAS sebagai media cetak dari masa ke masa, kedua adalah kemampuan KOMPAS untuk tetap eksis di era internet ini. Dalam dunia media cetak nama KOMPAS adalah media yang tidak bisa dianggap remeh KOMPAS adalah salah satu pionir media cetak nasional yang berhasil dalam beberapa era atau zaman, dalam era Orde Lama KOMPAS merupakan peletak komitmen pertama media cetak yang mandiri. Dalam era Orde Baru Kompas semakin menguatkan kaki kakinya sebagai media cetak yang terpercaya. Walau begitu perjalanan Kompas tak semudah yang dikira di era Orde Baru. Banyak lika-liku yang dihadapi oleh Kompas namun hal ini tidak memudarkan dewan direksi dari Kompas untuk tetap menjadikan kompas media cetak yang tak berpihak kemanapun dan berdiri atas dasar independensinya. Di masa reformasi Kompas adalah salah satu penggerak dari media-media cetak untuk mengabarkan tentang gerakan-gerakan reformasi di kala itu. Hal-hal diatas menggelitik rasa keingintahuan dari peneliti untuk meneliti lebih jauh apakah yang menjadi faktor utama kekuatan dari Kompas, terkhusus PT. Kompas Gramedia Sulawesi Selatan.
\end{abstract}

Kata Kunci: Gaya Kepemimpinan, Pimpinan, Manajemen Sumber Daya Manusia 


\section{2 | Bina Ekonomi}

\section{PENDAHULUAN}

PT. Sirkulasi Kompas Gramedia Makassar merupakan perusahaan yang sangat besar dan berskala nasional. Pada awalnya diterbitkan majalah bulanan Intisari pada 17 Agustus 1963 oleh Petrus Kanisius (PK) Ojong dan Jakob Oetama (JO), bersama J. Adisubrata dan Irawati SH. Majalah bulanan ini utamanya ditujukan untuk memberi bacaan bermutu dan membuka cakrawala masyarakat Indonesia.

Sejarah panjang dari PT. Kompas Gramedia, berawal dari, Intisari terbit dengan tampilan hitam putih, tanpa sampul, berukuran 14 x 17,5 cm, dan tebal 128 halaman. Meskipun demikian, Intisari mendapat sambutan baik dari pembacanya dan beroplah 11.000 eksemplar.

Hampir 3 tahun kemudian, tepatnya pada 28 Juni 1965, diterbitkan Surat Kabar Kompas yang berawal dari ide menerbitkan koran untuk melawan pers komunis. Kompas awalnya terbit sebagai surat kabar mingguan dengan 8 halaman, lalu terbit 4 kali seminggu, hingga kemudian dalam waktu 2 tahun telah berkembang menjadi surat kabar harian nasional dengan oplah 30.650 eksemplar. Nama Kompas sendiri adalah pemberian dari Ir. Soekarno, presiden RI kala itu, yang artinya penunjuk arah.

Dalam rangka memperkuat penyebaran produk dari penerbitan Kompas Gramedia (KG) dan menjadi pusat penjualan buku-buku impor di Indonesia, pada 2 Februari 1970 hadirlah Toko Buku Gramedia yang pertama. Sebagai langkah awal, dibuka sebuah toko kecil seluas 25 meter persegi di Jalan Gajah Mada, Jakarta Pusat. Hingga kini, Toko Buku Gramedia Gajah Mada tersebut masih beroperasi melayani para pelanggannya. Kini sudah lebih dari 100 toko buku tersebar di kota-kota besar Indonesia.

Awalnya, harian Kompas dicetak di percetakan PT Keng Po. Seiring oplah yang makin meningkat dan agar dapat menjamin Kompas bisa terbit di pagi hari, dipikirkan cara untuk memiliki usaha percetakan sendiri. Maka pada tahun 1971, didirikan Percetakan Gramedia di Jalan Palmerah Selatan, yang mulai beroperasi pada bulan Agustus 1972 dan diresmikan pada tanggal 25 November 1972 oleh Gubernur DKI Jakarta saat itu, Ali Sadikin.

Pada tahun 1997 dibangun sistem cetak jarak jauh (remote printing) sebagai terobosan teknologi untuk mempercepat distribusi harian Kompas di daerah. Sistem cetak jarak jauh pertama kali didirikan pada tahun 1997 di Bawen, kemudian dilanjutkan dengan kota-kota lainnya seperti Makasar (Oktober 1998), Surabaya (November 1999), Palembang (Juni 2001), Medan (Juni 2003), Banjarmasin (Agustus 2002), Bandung I (Februari 2006), Bandung II (Januari 2007), dan Bali (Maret 2009). Kini, Percetakan Gramedia juga melebarkan sayapnya ke flexible packaging printing dengan merek Metaform.

Berawal dari tujuan mulia untuk membuka cakrawala masyarakat Indonesia, Intisari telah hadir mengawali kiprah Kompas Gramedia sejak 17 Agustus 1963. Kini, Kompas Gramedia telah berkembang dan memiliki berbagai jenis usaha yang tersebar di seluruh Indonesia.

PT. Sirkulasi Kompas Gramedia (SKG) adalah salah satu dari sekian banyak anak perusahaan di bawah naungan kelompok usaha media terbesar di Indonesia, Kompas Gramedia. SKG yang mulai beroperasi tanggal 1 Januari 2009 merupakan hasil penggabungan seluruh Departemen Sirkulasi/Distribusi media di Kompas Gramedia. Unit usaha ini dibentuk sejalan dengan visi jangka panjang KG dalam memenangkan persaingan yang semakin ketat dan keras di masa mendatang. Persaingan di era sekarang mengarah ke persaingan antar grup perusahaan dimana yang bertanding di pasar adalah kekuatan 
bersama-sama dari produk-produk yang tergabung dalam masing-masing grup perusahaan induknya. KG yang mempunyai kekuatan range product yang sangat luas serta berpengalaman mengelola jaringan distribusi media cetak tentu harus bisa memanfaatkan modal ini dengan optimal.

SKG menangani operasional penjualan melalui kegiatan penyaluran dan peredaran seluruh media yang berjumlah lebih dari 70 merek surat kabar harian, tabloid maupun majalah, baik mingguan maupun bulanan. Sebagian besar media yang ditangani adalah pemimpin pasar di segmen masing-masing, diantaranya Harian Kompas, Warta Kota, tabloid Bola, Nova, Otomotif, majalah Bobo, Intisari, autobild, National Geographic Indonesia dan masih banyak lagi.

Wilayah operasi SKG meliputi seluruh wilayah Indonesia, dengan 11 Kantor Cabang (Branch Office), 6 Kantor Penjualan (Sales Office) dan jumlah karyawan organik 300 orang dan dibantu tenaga non organik lebih dari 500 orang. SKG menangani penjualan melalui jaringan distribusi keagenan konvensional maupun saluran kekinian yang berjumlah lebih dari 4000 agen, serta melayani penanganan pelanggan langsung (direct subscription).

Untuk PT. Sirkulasi Kompas Gramedia (SKG) Makassar yang terletak di Jl. Cendrawasih No. 430 Sambung Jawa, Mamajang, Kota Makassar, Sulawesi Selatan. Memiliki jumlah karyawan tetap sebanyak 13 orang, dan dibantu karyawan non organic sebanyak 17 orang dan juga melayani penanganan pelanggan langsung atau biasa disebut direct subscription.

PT. Sirkulasi Kompas Gramedia Makassar adalah perusahaan besar dan berskala nasional di bagian pemasaran. PT. Sirkulasi Kompas Gramedia Makassar memiliki peranan yang penting dalam menggerakkan pundi-pundi kehidupan untuk masyarakat Makassar dan sekitarnya. PT. Sirkulasi Kompas Gramedia Makassar telah dipercaya Lembaga Pemerintahan, baik di tingkat pusat maupun di daerah untuk melaksanakan berbagai program-program kerjanya termasuk dalam memberikan bacaan-bacaan yang bermutu dan berkualitas bagi semua elemen masyarakat,

Kinerja karyawan PT. Sirkulasi Kompas Gramedia yang maksimal sangatlah diharapkan oleh perusahaan. Perusahaan pasti menginginkan hasil yang maksimal yang diperoleh secara efektif dan efisien baik pada bagian pengelolaan sumber daya alam, sumber daya manusia dan sumber daya modal. Satu dari tiga sumber daya tersebut yang paling mempengaruhi kinerja atau output perusahaan adalah sumber daya manusia.

Pada perusahaan yang bergerak di bidang produksi, kinerja sumber daya manusia selalu dituntut untuk bekerja secara maksimal demi kemajuan perusahaan. Pengelolaan sumber daya manusia secara efektif dan efisien akan mendorong karyawan bekerja secara maksimal guna mencapai visi perusahaan yaitu menjadi perusahaan multinasional yang profesional dan mandiri. Perusahaan tidak bisa lepas dari peranan kinerja karyawan karena kinerja karyawan akan berbanding lurus dengan output pada perusahaan. Hal ini menunjukkan bahwa perusahaan sangat bergantung pada kinerja karyawan yang mana mereka harus selalu diperhatikan kebutuhannya dan tuntutannya agar karyawan selalu memiliki kinerja yang maksimal. Menurut Handoko (2001), kinerja karyawan merupakan suatu tindakan yang dilakukan karyawan dalam melaksanakan pekerjaan yang diberikan perusahaan.

\section{KAJIAN PUSTAKA}

2.1 Pengertian Gaya Kepemimpinan 


\section{4 | Bina Ekonomi}

Gaya pada dasarnya berasal dari bahasa Inggris "Style" yang berarti ciri khas seseorang yang mudah dikenali dan secara tidak langsung menjadi identitasnya. Tiap pemimpin akan mempunyai ciri khas masing - masing ada yang mempunyai gaya kepemimpinan sedikit-sedikit marah bila menemui celah kesalahan dari bawahannya.

Stoner, (2006) gaya kepemimpinan adalah cara pola pemimpin dalam memberikan instruksi atau perintah terhadap bawahannya untuk mencapai cita-cita perusahaan. Kepemimpinan dalam pengertian umum berarti proses dimana seseorang yang ditunjuk oleh kumpulannya untuk membimbing dan mengarahkan dalam rangka mewujudkan cita-cita bersama. Davis (2002), "kepemimpinan adalah proses membimbing, membantu orang lain untuk bekerja sama dengan antusias untuk mencapai tujuan". Sedangkan Malayu SP Hasibuan (2004), pengetahuan kepemimpinan adalah: "Cara seorang pemimpin mengontrol bawahan agar ikut bekerjasama dengan bekerja secara produktif untuk tercapainya tujuan perusahaan"

2.2 Teori-teori Kepemimpinan

Sejalan dengan berjalannya waktu kepemimpinan dipengaruhi oleh beberapa faktor dari seorang pemimpin, antara lain kemampuan, (kesadaran akan harkat diri), dari segi eksternal kepemimpinan dipengaruhi oleh pengikut, interaksi, dan iklim organisasi. G.R. Terry dalam Winardi (2000) membagi kepemimpinan menjadi 8 teori Antara lain:

a) Teori Otokratis (The Autocratic Theory)

Kepemimpinan menurut teori ini adalah bagaimana seorang pemimpin memerintah dengan cara otoriter atau diktatoran, dalam teori ini hukuman-hukuman merupakan bagian yang tak terelakkan dari kediktatoran seorang pemimpin.

b) Teori Psikologis (The Psychological Theory)

Pendekatan terhadap teori ini dimana pemimpin memberikan motivasi kepada bawahan untuk mengembangkan bakat dan merangsang kinerja karyawan untuk mencapai citacita organisasi dan memenuhi kebutuhan tujuan pribadi mereka.

c) Teori Sosiologis (The Sociological Theory)

Dalam teori ini ada anggapan pemimpin mampu dan harus bisa untuk mengatasi dan menghalau konflik dan hambatan organisatoris yang akan menggagalkan tujuan dari organisasi atau cita-cita perusahaan.

d) Teori Suportif (The Supportive Theory)

Dalam pendekatan ini pimpinan merasa setiap individu-individu pengikutnya berusaha sebaik-baiknya, pemimpin merasa sudah memimpin dengan baik melalui langkahlangkah untuk membantu kerja-kerja dari pengikutnya.

e) Teori Laissez Faire (The Laissez Faire Theory)

Berdasarkan teori ini, pimpinan memberikan kebebasan dalam bekerja pengikutnya tanpa ada batasan perintah yang mengikat bagi mereka.

f) Teori Perilaku Pribadi (The Personal-Behaviour Theory)

Pendekatan ini melakukan apa yang dilakukan oleh pemimpin dalam hal memimpin. Sumbangan pemikiran penting dalam teori ini adalah bahwa seorang pimpinan tidak bertindak sama ataupun seimbang dalam segala hal yang mereka hadapi.

g) Teori Sifat (The Trait Theory)

Teori ini memberikan memberikan sifat-sifat pemimpin antara lain :

1) Inisiatif

2) Energi atau rangsangan 
3) Intelegensia

4) Persuasif

5) Kreativitas

6) Kedewasaan emosional

7) Skill komunikatif

8) Kepercayaan pada diri sendiri

9) Perseptif

10) Partisipasi sosial

h) Teori Situasi (The Situational Theory)

Dalam teori ini menerangkan bahwa pemimpin berkarakter fleksibel dan tidak kaku untuk memutuskan sesuatu dan dalam situasi apapun.

\section{METODE}

Penelitian ini menggunakan teknik wawancara dari narasumber yang memang berkompeten, hal ini didasari karena peneliti lebih menginginkan kedalaman informasi langsung dari pelaku atau pemimpin-pemimpin PT.Kompas Gramedia agar dapat ditarik kesimpulan yang akurat tentang gaya kepemimpinan yang diadopsi oleh mereka dalam memimpin.

Wawancara dengan para pemimpin ini sangatlah beragam, karakter mereka pun beragam. Selain pimpinan peneliti juga mewawancarai beberapa karyawan tentang gaya kepemimpinan para pemimpin agar peneliti dapat melihat atau menilai dari perspektif bawahan tentang gaya kepemimpinan di PT.Kompas Gramedia.

\section{HASIL}

Dari beberapa wawancara para pemimpin PT. Kompas Gramedia Sulawesi Selatan mereka lebih banyak memilih pendekatan budaya, dimana mereka lebih memilih mengikuti kebiasaan dari budaya setempat dan menyusupkan sedikit budaya kerja mereka secara perlahan dan memastikan budaya kerja mereka diterima secara sukarela dan tidak ada unsur paksaan.

Ada pula pemimpin yang lebih memilih gaya "strike" dengan kata lain mereka lebih memaksakan apa yang menjadi keyakinan mereka, budaya kerja mereka kepada bawahannya. Namun demikian dari sisi karyawan gaya kepemimpinan ini banyak yang menentang walau tidak di ikuti dengan penentangan yang keras.

Namun demikian berbagai macam gaya kepemimpinan ini adalah hasil dari aktualisasi pemimpin untuk mewujudkan visi dan misi perusahaan, dengan berbagai macam gaya kepemimpinan inilah Kompas Gramedia menjadi suatu perusahaan yang sangat tangguh di tengah badai ekonomi di tahun 1998-2000, dimana bisa dipastikan perusahaan yang kurang sehat manajemennya akan mengalami gulung tikar.

Kepemimpinan adalah salah satu faktor Kompas Gramedia Selamat dari tekanan Orde lama dan orde baru tetap independen di jalur jurnalis yang jujur, akomodatif terhadap rakyat, dan tak sungkan dalam mengkritik di kalangan politik.

Dalam era digital ini pun Kompas Gramedia tetap eksis dalam produksi koran, majalah, tabloid dan lain-lain, hal ini dikarenakan banyak pemimpin Kompas percaya bahwa koran tidak akan pernah hilang ditelan masa.

Mereka percaya manusia juga membutuhkan informasi secara manual atau klasik mengapa demikian, karena pada dasarnya manusia adalah makhluk yang terbiasa dengan 


\section{6 | Bina Ekonomi}

sesuatu, dan kebiasaan membaca koran adalah kebiasaan yang tak kan pernah hilang. Inilah yang membuat keyakinan pimpinan bahwa Kompas Gramedia akan selamat dari zaman ke zaman.

\section{DISKUSI}

Beberapa ahli mungkin meyakini beberapa metode kepemimpinan dari negaranegara barat akan menyokong atau membuat mereka berhasil mempertahankan perusahaanya. Namun tidak demikian dengan yang terjadi di Indonesia.

Gaya kepemimpinan adopsi dari para ahli asing bahkan mungkin tidak banyak yang cocok dengan perusahaan di Indonesia, mengapa demikian ? karena adopsi dari barat akan menimbulkan celah budaya. Iya celah budaya yang berbeda inilah yang mengakibatkan banyaknya gaya kepemimpinan dari luar banyak gagal di Indonesia.

Kompas Gramedia sebagai salah satu perusahaan Nasional terkemuka meyakini bahwa gaya kepemimpinan di satu perusahaan akan menciptakan kenyamanan bagi pegawai dan akan berimbas dengan peningkatan kinerja dari pegawai.

Maka dari itu banyak pemimpin dari Kompas Gramedia menggunakan pendekatan budaya bagi pegawainya. Dengan pendekatan budaya pegawai akan merasa di manusiakan dan jarak antara pegawai dan pimpinan hampir tidak ada, mereka bisa mengemukakan ide atau gagasanya demi kemajuan dan cita-cita perusahaan. Hal inilah yang mengakibatkan Kompas Gramedia bisa bertahan ditengah arus perubahan zaman.

\section{KESIMPULAN}

Kepemimpinan adalah cara interaksi dari pemimpin ke pegawai untuk menciptakan kesinambungan yang sejalan dan seiring demi terwujudnya cita-cita atau visi misi dari perusahaan.

Kepemimpinan yang baik bukan berarti satu perusahaan mengadopsi dari teoriteori yang telah ada dan dipelajari di bangku kuliah, namun teori-teori itu dapat dijadikan gambaran umum bagi pemimpin, tapi tidak serta merta bisa teraplikasikan dalam dunia kerja nyata.

Dikarenakan kepemimpinan secara nyata adalah dinamis dan tidak bersifat mutlak secara teori. Karena kepemimpinan merupakan ilmu sosial, pembahasan tentang manusia bukan sekedar teori namun harus menyentuh dari hati ke hati.

Para pemimpin Kompas Gramedia sadar dan yakin bahwa menghadapi manusia bukan dengan teori, namun dengan pendekatan secara manusiawi. Mereka lebih cenderung bergerilya dari sisi budaya dan sosial, mengapa demikian karena dengan pendekatan ini karyawan akan merasa memiliki dan akan ikut serta membesarkan dan mempertahankan perusahaan dengan sumbangsih kinerja yang semakin hari semakin meningkat.

Para pemimpin Kompas Gramedia sangat jarang sekali memutuskan suatu kesalahan dari pegawainya dengan hukuman berupa pemecatan, bahkan dalam kondisi krisis pun Kompas Gramedia tidak merumahkan pegawainya.

Pendekatan secara budaya dan merangkul inilah yang menjadi salah satu faktor kekuatan Kompas Gramedia di tengah arus perubahan zaman. 


\section{DAFTAR PUSTAKA}

Handoko. T.Hani. 2001.Manajemen Personalia dan Sumber Daya Manusia,Edisi II.BPFE Yogyakarta : Yogyakarta

A.F. Stoner. 2006. Manajemen Sumber Daya Manusia. Jakarta: Bumi Aksara.

Davis, Keith, and Newstrom, John,W. 2002. Organizational Behavior At Work. 11 edition. New York. Mc Graw - Hill

Hasibuan, Malayu S.P, 2004. Manajemen Sumber Daya Manusia. Cetakan ke Tujuh, edisi revisi, PT. Bumi Aksara. Jakarta.

R.Terry, George. Prinsip- Prinsip Manajemen. Jakarta: Bumi Aksara, 2006) 